\title{
Outcome of Microlaryngeal Surgery for Vocal Fold Polyp on Quality of Voice
}

\author{
${ }^{1}$ HS Sabari Nath, ${ }^{2}$ Jayakumar R Menon, ${ }^{3}$ Manju E Issac, ${ }^{4}$ Ragitha Binukrishnan, ${ }^{5}$ Akhila Sebastian
}

\section{ABSTRACT}

Aim: To study the outcome of microlaryngeal surgery for vocal fold polyp on quality of voice with voice handicap index-10 (VHI-10).

Objective: Microlaryngeal surgery for vocal fold polyp will improve the quality of voice.

\begin{abstract}
Materials and methods: This is a nonrandomized prospective study with a quasi-experimental design. A total of 36 patients presenting with vocal cord polyp and who underwent a microlaryngeal surgery for the same from March 2016 to August 2016 were included in the study. All the patients were given a self-reporting questionnaire consisting of 10 questions - VHI$10-$ and asked to score it. The same questionnaire was given 6 weeks postmicrolaryngeal surgery to these patients and both scores were compared.
\end{abstract}

Results: The mean age of the study population was $44.67 \pm 0.34$ with the maximum number of patients in the age group 31 to 50 . Out of the 36 patients, 27 were males and 9 females. A total of $22(61 \%)$ patients had right-sided polyp and $14(39 \%)$ had left-sided polyp. The majority of the patients were voice professionals, with the maximum number being that of teachers. The mean preoperative and postoperative $\mathrm{VHI}-10$ was $30.36 \pm 6.42$ and $1.11 \pm 1.76$ respectively. The reduction in preoperative and postoperative scores gave a p-value of $<0.05$ at a confidence interval of $95 \%$.

Keywords: Microlaryngeal surgery, Phonosurgery, Polyp, Quality of voice, Vocal cord lesions.

How to cite this article: Nath HSS, Menon JR, Issac ME, Binukrishnan R, Sebastian A. Outcome of Microlaryngeal Surgery for Vocal Fold Polyp on Quality of Voice. Int J Phonosurg Laryngol 2017;7(1):13-15.

\section{Source of support: Nil}

Conflict of interest: None

\footnotetext{
${ }^{1}$ Assistant Professor, ${ }^{2}$ Senior Consultant, ${ }^{3}$ Associate Consultant ${ }^{4}$ Registrar, ${ }^{5}$ Voice and Swallowing Pathologist

${ }^{1}$ Department of ENT and Laryngology, Azeezia Institute of Medical Science and Research, Kollam, Kerala, India

${ }^{2-5}$ Department of Laryngology, Kerala Institute of Medical Sciences, Thiruvananthapuram, Kerala, India

Corresponding Author: HS Sabari Nath, Assistant Professor Department of ENT and Laryngology, Azeezia Institute of Medical Science and Research, Kollam, Kerala, India, Phone: +914742722567, e-mail: drsabarinath@icloud.com
}

\section{INTRODUCTION}

Vocal fold polyps are among the most common benign lesions of true vocal folds, which require surgery. ${ }^{1}$ Vocal polyps are usually solitary arising from the edge of the vocal folds. ${ }^{2}$ Phonotrauma is an important etiological factor for vocal fold polyp. Phonotrauma includes vocal overuse, which is seen in voice-demanding professionals, in vocal abuse, or in work environments that are noisy. ${ }^{1}$ Voice abuse is characterized by forced voice production due to strain in the head, neck, and shoulder region producing a hoarse quality of voice. ${ }^{3} \mathrm{In}$ professional voice users, varix or capillary ectasia occurs due to microtrauma, which leads to neoangiogenesis and subsequent microhemorrhage into the superficial lamina propria. ${ }^{4}$ These lead to localized edema, which later organizes to a hyalinized stroma, presenting as a polyp..$^{5}$ Vocal fold polyps occur more in males in the age group of 30 to 40 years. ${ }^{6}$ In addition to the acute insult to the vocal folds, smoking, laryngopharyngeal reflux, and anticoagulant therapy predispose this condition among those who abuse or misuse voice. Vocal fold polyp usually causes varying degrees of hoarseness and vocal strain, thus interfering in day-to-day activities. In professional voice users, there may be pitch break and loss of range along with breathy or a hoarse voice. About $80 \%$ of vocal fold polyps are unilateral, occurring on the free edge or the undersurface of the vocal fold at the anterior or middle third; $20 \%$ are bilateral or multiple. ${ }^{1}$

The voice handicap index-10 (VHI-10) is easily selfadministered and scored, quickly at the time of evaluation while preserving the original VHI's utility and validity. ${ }^{7}$ The aim of the research was to analyze the improvement in quality of voice in terms of $\mathrm{VHI}$ among those who underwent microlaryngeal surgery for vocal fold polyp.

\section{AIM}

To study the outcome of microlaryngeal surgery for vocal cord polyp on quality of voice with VHI-10.

\section{OBJECTIVE}

Microlaryngeal surgery for vocal fold polyp will improve the quality of voice. 


\section{MATERIALS AND METHODS}

\section{Study Design}

Nonrandomized prospective study with quasiexperimental design was undertaken.

\section{Study Population}

All the patients who underwent microlaryngeal surgery for vocal fold polyp in the senior author's voice clinic from March 2016 to August 2016 were included. Those who were not willing for giving consent and those with other coexisting laryngeal pathologies were excluded from the study. All the patients were asked to fill up a preoperative survey, a self-reporting questionnaire with 10 questions (VHI-10). All the patients underwent microlaryngeal surgery for vocal fold polyp with minimicroflap technique. These patients were again given the same questionnaire 6 weeks postsurgery when they were called for follow-up.

\section{VHI Survey}

All the patients were assessed with a self-reporting questionnaire, VHI-10, preoperatively and 6 weeks postoperatively. The VHI-10 consists of 10 entries, and patients have to score each problem with the appropriate option representing the frequency of occurrence for each problem: 0 for "no"; 1 for "rarely"; 2 for "sometimes"; 3 for "regular"; and 4 for "always." The VHI-10 score is the sum of the score of 10 entries, which range from 0 to 40 points. The higher the VHI-10 score is, the more serious is the subjective assessment of patients on quality of voice.

\section{Statistical Method}

The results were subject to statistical analysis with software Statistical Package for the Social Sciences

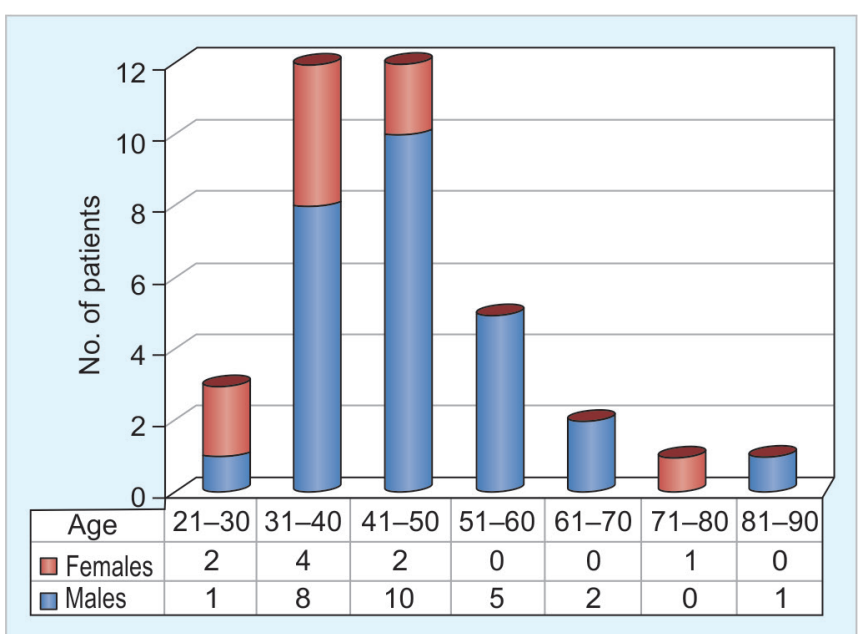

Graph 1: Distribution of patients based on age and sex
22.0.0 version. Data were expressed as mean \pm standard deviation. Paired t-test was applied for statistical significance.

\section{RESULTS}

A total of 36 patients in the age group of 25 to 82 , with a mean age of $44.67 \pm 0.34$ years, were included in the study. The maximum number of patients were in the age group 31 to 50 (Graph 1). Out of these 36 patients, 27 were males and 9 females. A total of $22(61 \%)$ patients had right-sided polyp and 14 (39\%) had left-sided polyp. The majority of the patients were voice professionals, with the maximum number being teachers followed by businessman, advocate, priest, supervisors, doctors, executives, driver, housewife, and one retired employee (Graph 2). Two housewives and one retired employee had voice overuse as they have small kids at home. Mean VHI10 preoperatively and postoperatively was compared. The mean preoperative and postoperative VHI-10 was $30.36 \pm 6.42$ and $1.11 \pm 1.76$ respectively (Table 1 ). The reduction in preoperative and postoperative scores gave a p-value of $<0.05$ at a confidence interval of $95 \%$.

\section{DISCUSSION}

In our study, the majority of the patients were in the age group of 31 to 40 and 41 to 50 (12 patients each). In a study by Reddy et $\mathrm{al}^{8}$ on 50 patients with vocal fold polyp and another study by Mehta et $\mathrm{al}^{9}$ on 50 patients, it was shown that the maximum number of patients were in the age group of 31 to 40 , which is followed by the 41 to 50 age group (Table 2). This is the most active and productive period of life-involved in various social, economics, and professional work.

In all the studies, the prevalence of vocal fold polyp is more for males; the reason is that males may be overusing

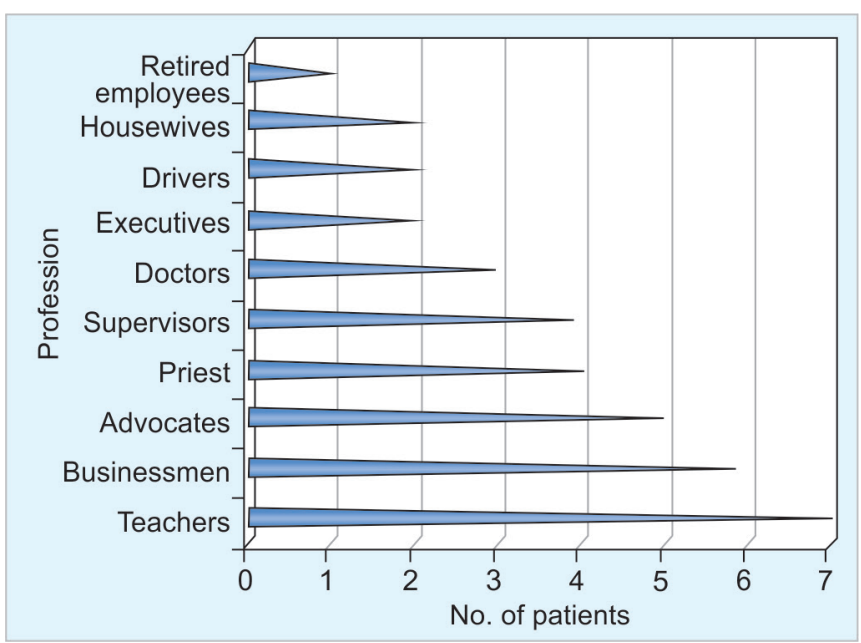

Graph 2: Distribution of patients based on profession 
Table 1: Comparison of mean VHI preoperatively and postoperatively

\begin{tabular}{lll}
\hline VHI & $\begin{array}{l}\text { Preoperative VHI } \\
(\text { Mean } \pm \text { SD) }\end{array}$ & $\begin{array}{c}\text { Postoperative VHI } \\
\text { (Mean } \pm \text { SD) }\end{array}$ \\
\hline My voice makes it difficult for people to hear me & $3.52 \pm 0.84$ & $0.11 \pm 0.31$ \\
I ran out of air when I talk & $2.27 \pm 1.46$ & $0.19 \pm 0.52$ \\
People have difficulty understanding me in a noisy room & $3.50 \pm 0.84$ & $0.19 \pm 0.82$ \\
The sound of my voice varies throughout the day & $2.94 \pm 1.47$ & $0.08 \pm 0.36$ \\
My family has difficulty hearing me when I call them at home & $3.02 \pm 1.31$ & $0.02 \pm 0.16$ \\
I use the phone less often than I would like to & $2.97 \pm 1.27$ & $0.03 \pm 0.16$ \\
I am tensed when talking to others because of my voice & $3.02 \pm 1.36$ & $0.13 \pm 0.48$ \\
I tend to avoid a group of people because of my voice & $3.00 \pm 1.30$ & $0.27 \pm 0.70$ \\
People seem irritated with my voice & $2.47 \pm 1.57$ & 0 \\
People ask "What's wrong with your voice?" & $3.61 \pm 0.83$ & $1.11 \pm 1.76$ \\
VHI-10 & $30.36 \pm 6.42$ & $1.11 \pm 1.76$ \\
\hline
\end{tabular}

Table 2: Comparison of age of patients with the studies of Reddy et $\mathrm{al}^{8}$ and Mehta et $\mathrm{al}^{9}$

\begin{tabular}{llll}
\hline Age group & $\begin{array}{l}\text { Our study } \\
n=36\end{array}$ & $\begin{array}{l}\text { Reddy et al } \\
n=50\end{array}$ & $\begin{array}{l}\text { Mehta et al } \\
n=50\end{array}$ \\
\hline $31-40$ & $33.33 \%$ & $50.0 \%$ & $32.0 \%$ \\
$41-50$ & $33.33 \%$ & $12.0 \%$ & $26 \%$ \\
\hline
\end{tabular}

or abusing their voice more for professional or personal needs.

In our study, the majority of the patients were professional voice users (Graph 2). Out of the 36 patients, 7 were teachers followed by businessmen (6), advocates (5), priests (4), supervisors (4), doctors (3), executives (2), drivers (2), housewives (2), and a retired employee (1). Among the 4 priests, 2 were using Arabic language for preaching. Among the supervisors, 3 were in construction field and one in the airport. Both the places have a lot of background noise, which inevitably leads to voice abuse. Both housewives and one retired employee confessed of voice abuse at home, as they had small kids at home.

When we compared the outcome of our microlaryngeal surgery for vocal fold polyp on quality of voice using VHI-10, almost all the patients regained normal voice (Table 3). The normative value of VHI-10 is $2.83 .{ }^{10}$ In our study, the mean postoperative VHI-10 was $1.1 \pm 1.76$ with a p-value of $<0.005$ at a confidence interval of $95 \%$ when comparing it with the preoperative VHI-10, which implies a normal value postmicrolaryngeal surgery.

\section{CONCLUSION}

- Vocal fold polyps have a high impact on quality of voice/life, which can be measured using VHI-10.
Table 3: Comparison of preoperative and postoperative VHI-10

\begin{tabular}{llll}
\hline & & Reddy et al $^{8}$ & Mehta et al \\
& Our study & $n=50$ & $n=50$ \\
\hline Preoperative VHI-10 & $30.36 \pm 6.42$ & $34.23 \pm 7.36$ & $36.83 \pm 2.36$ \\
Postoperative VHI-10 & $1.11 \pm 1.76$ & $7.24 \pm 4.67$ & $10.64 \pm 7.43$ \\
\hline
\end{tabular}

- Microlaryngeal surgery for vocal fold polyp is very effective in regaining the quality of voice.

\section{REFERENCES}

1. Benjamin B. Vocal cord polyps. In: Endolaryngeal surgery. London: Mosby; 1988. p. 237-240.

2. McGlashan J. Disorders of voice. Chapter 167. In: Gleeson MJ, Clarke RC, editors. Scott-Brown's Otorhinolaryngology, head and neck surgery. 7th ed. London: Hodder Arnold; 2008. p. 2192-2210.

3. Aronson AE, Bless DM. Clinical voice disorders. New York: Thieme Medical Publishers, 2009. p. 174-175.

4. Roychoudhury A. Nodules and polyps. In: Nerurkar NK, Roychoudhury A, editors. Textbook of laryngology. 1st ed. New Delhi: Jaypee Brothers; 2017. p. 147-154.

5. Altman KW. Vocal fold masses. Otolaryngol Clin North Am 2007 Oct;40(5):1091-1108.

6. Kleinsasser O. Pathogenesis of vocal fold polyps. Ann Otol Rhinol Laryngol 1982 Jul-Aug;91(4 Pt 1):378-381.

7. Rosen CA, Lee AS, Osborne J, Zullo T, Murry T. Development and validation of the voice handicap index-10. Laryngoscope 2004 Sep;114(9):1549-1556.

8. Reddy DS, Rathod JB, Dham R, Babu AS, Nagaraj K, Srinivas K, Kumuda C, Reddy BS. Benign lesions of larynx: a clinical study of 50 cases. J Evid Based Med Healthc 2016;3(2): 72-77.

9. Mehta KS, Khan MA, Mattoo RR, Khan MA, Ahmad R. Clinical analysis and voice handicap index-10 (VHI-10) of patients with vocal cord polyps and nodules. Int J Contemp Med Res 2016;3(4):1229-1231.

10. Arffa RE, Krishna P, Gartner-Schmidt J, Rosen CA. Normative values for voice handicap index-10. J Voice 2012;26(4):462-465. 